\title{
Immunohistochemical Detection of Cyclin D1 Using Optimized Conditions Is Highly Specific for Mantle Cell Lymphoma and Hairy Cell Leukemia
}

Roberto N. Miranda, M.D., Robert C. Briggs, Ph.D., Marsha C. Kinney, M.D., Pat A. Veno, Ph.D., Richard D. Hammer, M.D., John B. Cousar, M.D.

Department of Pathology, Truman Medical Center and University of Missouri-Kansas City (RNM, PAV), Kansas City, Missouri; Department of Pathology and Division of Hematopathology (RCB, MCK, JBC), Vanderbilt University Medical Center, Nashville, Tennessee; and Clinical Pathology Associates (RDH), Austin, Texas.

Mantle cell lymphoma (MCL) is more aggressive when compared with other lymphomas composed of small, mature B lymphocytes. Cyclin D1 is overexpressed in MCL as a result of the translocation t(11;14)(q13;q32). Cyclin D1 immunohistochemistry in fixed, paraffin-embedded tissue contributes to the precise and reproducible diagnosis of MCL without the requirement of fresh tissue. However, its use in bone marrow biopsies is not well established. In addition, increased levels of cyclin D1 mRNA have been found in hairy cell leukemia but have not consistently been detected by immunohistochemistry. We used a polyclonal antibody and heatinduced antigen retrieval conditions to evaluate 73 fixed, paraffin-embedded bone marrow, spleen, and lymph node specimens with small B-cell infiltrates, obtained from 55 patients. Cyclin D1 was overexpressed in 13/13 specimens of MCL (usually strong, diffuse reactivity in most tumor cells) and in 14/14 specimens of hairy cell leukemia (usually weak, in a subpopulation of tumor cells). No reactivity was detected in five cases of B-chronic lymphocytic leukemia; five cases of splenic marginal zone lymphoma; six cases of nodal marginal zone cell lymphoma; two cases of gastric marginal zone cell lymphoma; or ten benign lymphoid infiltrates in bone marrow, spleen, or lymph nodes. In summary, although the total number of studied cases is small and a larger series of cases may be required to confirm our data, we present optimized immunohistochemical conditions for cyclin D1 in fixed, paraffin-embedded tissue that can be useful in distinguishing MCL and

Copyright (C) 2000 by The United States and Canadian Academy of Pathology, Inc.

VOL. 13, NO. 12, P. 1308, 2000 Printed in the U.S.A.

Address reprint requests to: Roberto N. Miranda, M.D.; Department of Pathology; Truman Medical Center, 2301 Holmes Street, Kansas City, MO 64108; e-mail: tmcmiranda@aol.com; fax: 816-556-3942. hairy cell leukemia from other small B-cell neoplasms and reactive lymphoid infiltrates.

KEY WORDS: Bone marrow, Cyclin D1, Hairy cell leukemia, Immunohistochemistry, Lymph node, Lymphoma, Mantle cell lymphoma.

Mod Pathol 2000;13(12):1308-1314

Lymphoproliferative disorders of small, mature B lymphocytes are diverse entities with different clinical manifestations and prognosis. Their diagnosis and classification requires a combination of histopathologic, immunologic, and molecular data (13 ). Within this group, it is important to recognize that mantle cell lymphoma (MCL) has an aggressive course with a significant decrease in 5-year survival $(4,5)$.

Cyclin D1 is a cell cycle protein that is overexpressed in MCL as a result of the translocation $\mathrm{t}(11 ; 14)$ (q13;q32), which involves the immunoglobulin heavy chain gene on Chromosome 14 and a region on Chromosome 11 designated $b c l-1(6,7)$. The oncogene cyclin D1 is telomeric to the breakpoint regions and, as a result of the translocation, becomes overexpressed in lymphocytes when normally it is absent or present only at very low levels (8). Cyclin D1 protein binds to a cell cycle kinase p34 ${ }^{\text {cdc2 }}$ and drives cells from $G_{1}$ into the $S$ phase. Thus, abnormally expressed cyclin D1 may contribute to deregulated cell proliferation (6-8).

Recent studies have established the usefulness of cyclin D1 immunohistochemistry in fixed tissue, particularly lymph nodes and soft tissues (7). Only one report addresses its use in bone marrow (BM) specimens, but several limitations and technical problems were acknowledged (9). Also, increased levels of cyclin D1 mRNA have been detected in hairy cell leukemia (HCL), but the results of immu- 
nohistochemical studies for cyclin D1 protein have not been consistent (9).

We have used a new antibody with optimal heatinduced epitope retrieval (HIER) to evaluate wellcharacterized, small B-cell infiltrates in BM, spleen, and lymph node specimens. Particular emphasis was placed on marrow specimens, where involvement may be subtle and must be distinguished from reactive lymphoid aggregates. Despite the small number of studied cases, our results show that MCL and HCL overexpress cyclin D1 with a characteristic pattern of reactivity; therefore, cyclin D1 immunohistochemistry is a reproducible, highly sensitive, and reliable technique to evaluate small B-cell lymphoid infiltrates of the BM, spleen, and lymph node in fixed tissue.

\section{MATERIALS AND METHODS}

\section{Case Selection}

BM, lymph node, and spleen specimens were obtained from the Division of Hematopathology files at Vanderbilt University Medical Center. A total of 73 different specimens from 55 patients were analyzed. Tissues were routinely fixed in buffered formalin or B5 and paraffin embedded. Bone marrow core biopsies were fixed in B5 for 1 hour, transferred to buffered formalin, and then decalcified overnight using $5 \%$ formic acid. Most specimens were 3 years old or less, but some specimens were up to 15 years old. Histologic features of all cases were studied by using hematoxylin and eosin and periodic acid-Schiff's stains. Cases of MCL, HCL, nodal marginal zone cell lymphoma (parafollicular or monocytoid B cell lymphoma), B-cell chronic lymphocytic leukemia/small lymphocytic lymphoma (B-CLL/SLL), and splenic marginal zone cell lymphoma (SMZL) were diagnosed according to established histopathologic and immunophenotypic criteria $(1,10,11)$. Ten specimens with reactive processes that included seven BM biopsies, one spleen, and two lymph nodes served as negative controls.

There were 25 specimens obtained from 13 patients with MCL; specimens included 2 spleen resections, 2 lymph nodes, and 1 soft tissue of orbit, as well as $12 \mathrm{BM}$ core biopsies and 8 aspirate clot sections. The BM specimens were obtained from 10 different patients and, for tabulation purposes, included 10 core biopsies and 6 aspirate particle sections. Histopathologic criteria and flow cytometric demonstration of a B-cell population with clonal surface immunoglobulin, CD5+, and lack of CD23 established the diagnoses.

Twenty specimens obtained from 14 patients with HCL included $13 \mathrm{BM}$ core biopsies and 7 spleen resections. The BM biopsies were obtained from 10 different patients; none had an aspirate clot section due to dry taps. Diagnoses were established by histopathologic criteria in all cases and by typical hairy cell morphology on Wright's stained smears (10 cases). In addition, diagnoses were supported by at least one of the following: flow cytometry immunophenotype (monotypic B cells coexpressing CD11c and CD25; 4 cases); tartrateresistant acid phosphatase positivity (10 cases); or DBA44 immunoreactivity was detected in 10/10 cases tested.

Our intention for using core biopsies and clot sections, as well as occasionally nodes or spleen specimens from the same patients in cases of MCL and HCL, was to provide evidence on consistency in the reactivity, as a result of formalin or B5 fixation or decalcification. We have included in this data three BM core biopsies of HCL patients and two core biopsies and clots of MCL patients obtained in follow-up visits to evaluate the possibility of change of reactivity over time.

\section{Evaluation of Histopathologic Findings in BM Specimens}

Tumor cell infiltrates were evaluated semiquantitatively in BM specimens of cases of MCL and HCL. The pattern of infiltration was defined as discrete small collections of lymphocytes with interstitial interspersed hematopoietic elements or nodular lymphoid aggregates or as diffuse replacement of the marrow space. The extent of involvement was also graded according to the percentage of lymphocytes relative to the overall BM cellularity: $<5 \%, 5$ to $25 \%, 26$ to $50 \%$, and $>50 \%$.

\section{Immunohistochemical Studies}

Four-micrometer-thick paraffin-embedded tissue sections were deparaffinized, and the endogenous peroxidase was quenched with $3 \% \mathrm{H}_{2} \mathrm{O}_{2}$ in methanol. The sections were then hydrated through gradient alcohols and phosphate buffered saline. Slides were placed in $10 \mathrm{~mm}$ citrate buffer and heated for 20 minutes in a $1500-\mathrm{W}$ microwave oven (Radarange Model RS-40; Amana, Amana, IA) at the full power setting, operating at $2.45 \mathrm{GHz}$ (HIER; 12). After washing, sections were exposed to $0.01 \%$ trypsin (Sigma Chemical Co, St. Louis, MO) for 5 seconds. Nonspecific protein-binding sites were blocked with $1 \%$ bovine serum albumin, $10 \%$ bovine calf serum, and phosphate buffered saline (blocking solution) for 30 minutes. Slides from each case were exposed to 1:100 dilution of $\mathrm{H} 295$ rabbit polyclonal antibody (Santa Cruz Biotechnology, Santa Cruz, CA) for 2 hours at room temperature. The antibody is affinity purified, raised against recombinant protein corresponding to amino acids 1 
to 295 , representing the full length of cyclin D1 of human origin. This antibody is cross-reactive with mouse and rat cyclin D1. Blocking solution was used as a negative control on duplicate slides. An avidin-biotin-peroxidase complex (Supersensitive Immunodetection System; Biogenex, San Ramon, CA) with 3,3'-diaminobenzidine as a chromogen was used for detecting antibody binding. Secondary antibody was a biotinylated goat secondary antiimmunoglobulins of mouse, rabbit, guinea pig, and rat primary antibodies.

The intensity of staining was graded as weak, moderate, or strong, and the number of cells positive was scored as $<5 \%, 5$ to $25 \%, 26$ to $50 \%$, or $>50 \%$.

\section{RESULTS}

\section{Histopathologic Findings in BM Specimens}

The histologic features of the 10 cases of MCL and 10 cases of HCL are summarized in Table 1.

\section{Mantle Cell Lymphoma}

The infiltrate was interstitial in one case, involved multiple aggregates in seven cases, and was diffuse in two cases. Tumor cells occupied $>50 \%$ of the marrow cellularity in four cases, 25 to $50 \%$ in no cases, 5 to $25 \%$ in five cases, and $<5 \%$ in one case. Two cases diagnosed with the blastoid variant of MCL were included, and both had a diffuse pattern of infiltration.

TABLE 1. Histopathologic Findings and Cyclin D1 Reactivity in Bone Marrow of Mantle Cell Lymphoma and Hairy Cell Leukemia Cases

\begin{tabular}{lcc}
\hline & $\begin{array}{c}\text { Mantle Cell Lymphoma } \\
(n=10) \\
\text { Number of Cases }\end{array}$ & $\begin{array}{c}\text { Hairy Cell Leukemia } \\
(n=10) \\
\text { Number of Cases }\end{array}$ \\
\hline Specimen & 10 & 10 \\
$\quad$ Core biopsy & 6 & 0 \\
$\quad$ Aspirate clot & 1 & \\
Pattern of involvement & 7 & 4 \\
$\quad$ Interstitial & 2 & 0 \\
Aggregates & 1 & 6 \\
Diffuse & 5 & 0 \\
Involvement & 0 & 3 \\
1-4\% & 4 & 2 \\
5-24\% & & 5 \\
25-49\% & & \\
50-100\% & 2 & 5 \\
Intensity of Cyclin D1 & 7 & 5 \\
$\quad$ Reactivity & 1 & 0 \\
Weak & & \\
Moderate & 0 & 0 \\
Strong & 2 & 5 \\
\% Cyclin D1+ cells* & 0 & 5 \\
1-4\% & 8 & 0 \\
5-24\% & & \\
25-49\% & & \\
$>50 \%$ & &
\end{tabular}

* Percentage of immunoreactive lymphocytes of total lymphocytes in the infiltrate.

\section{Hairy cell leukemia}

The infiltrates were interstitial in four cases and diffuse in six cases. Tumor cells occupied $>50 \%$ of the marrow cellularity in five cases, 25 to $50 \%$ in two cases, and 5 to $25 \%$ in three cases.

\section{Immunohistochemical Studies}

\section{Mantle cell lymphoma}

All 25 specimens of MCL were reactive, including 20 BM specimens (12 core biopsies, plus 8 that also had aspirate clot sections). All these specimens were obtained from 13 different patients; thus, the total reactivity was $13 / 13$. There was strong nuclear reactivity in all spleen, node, and orbit specimens (Fig. 1). Cyclin D1 staining was useful in identifying focal nodal involvement or follicular colonization by the tumor cells. Moderate staining was noted in the cytoplasm and nuclei of some endothelial cells.

Overall intensity of reactivity in BM specimens was weaker (Table 1 ), being strong in $1 / 10$, moderate in $7 / 10$, and weak in $2 / 10$ (Fig. 2). More than $50 \%$ of neoplastic cells reacted in $8 / 10$ cases, and between 5 and $25 \%$ of neoplastic cells reacted in $2 / 10$ cases (Fig. 3 ). The six cases having core biopsy

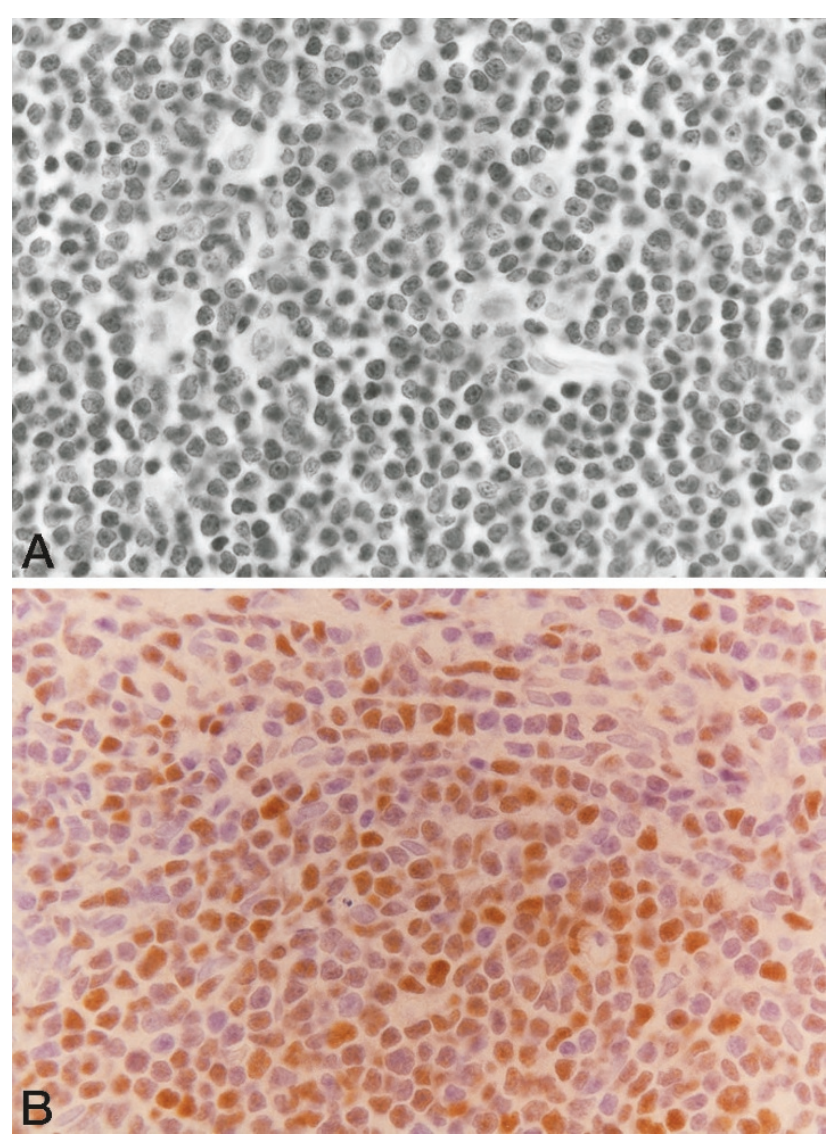

FIGURE 1. Soft tissue of the orbit infiltrated by mantle cell lymphoma. A, Hematoxylin and eosin staining. B, Cyclin D1 immunohistochemistry showing strong reactivity in most lymphocyte nuclei. $630 \times$. 

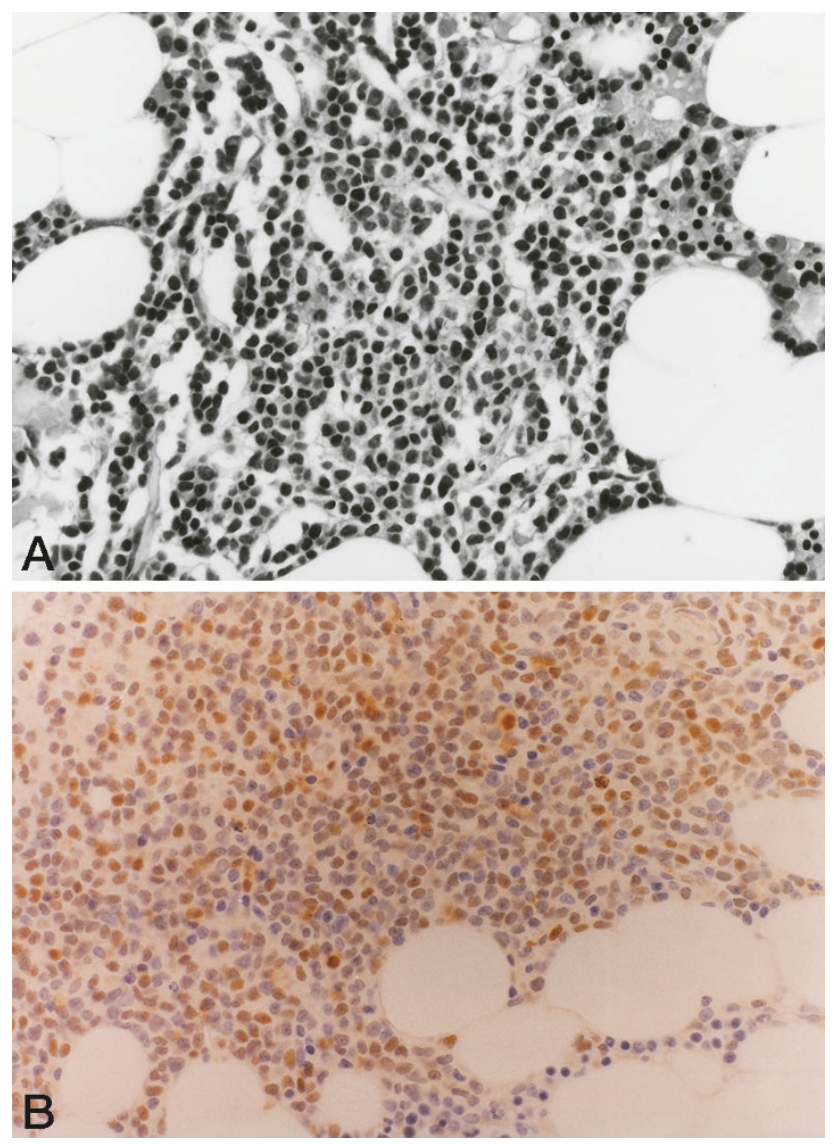

FIGURE 2. Bone marrow infiltrated by mantle cell lymphoma, diffuse lymphoid infiltrate. A, Periodic acid-Schiff's stain. B, Cyclin D1 immunohistochemistry showing moderate reactivity in most lymphocyte nuclei. $400 \times$.

and aspirate clot sections at the same time had identical pattern of reactivity. A rare mononuclear cell was reactive with cyclin D1 in residual normal BM or lymph node.

\section{Hairy cell leukemia}

Twenty of 20 specimens of HCL were reactive (Table 2). These specimens were obtained from 14 different patients; thus, the total reactivity was 14/ 14 . The reactivity was rather weak to moderate in the spleen specimens, and about 25 to $50 \%$ of neoplastic cells had reactivity. Among the $10 \mathrm{BMs}$, the intensity of reactivity was weak in five cases and moderate in five cases. More than $50 \%$ of neoplastic cells were not reactive; between 25 and $50 \%$ of neoplastic cells were reactive in five cases (Fig. 4), and $<25 \%$ of neoplastic cells were reactive in five cases.

\section{Other lymphoproliferative disorders}

No reactivity was detected in five cases of SMZL (spleen resections), five cases of B-CLL/SLL (two $\mathrm{BM}$, two spleen resections and one node), six cases of nodal marginal zone lymphoma, and two cases

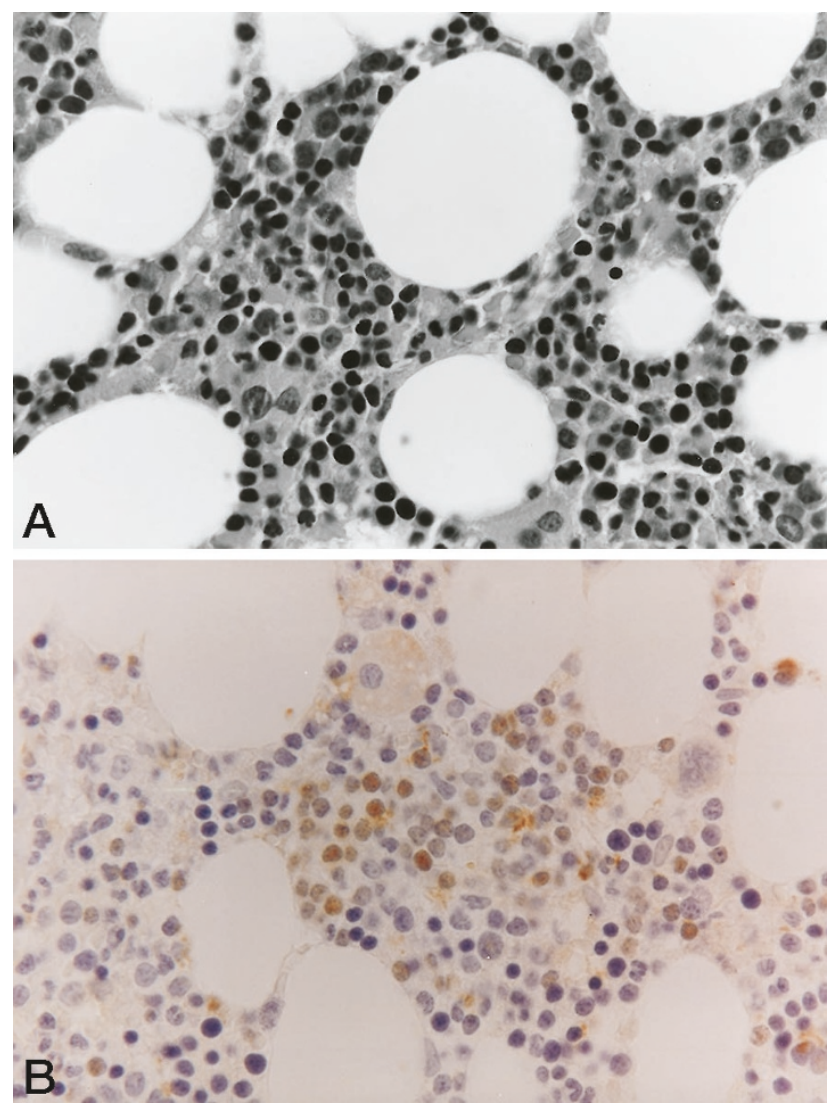

FIGURE 3. Bone marrow with focal interstitial lymphoid infiltrate. This figure illustrates the usefulness of cyclin D1 overexpression in detecting subtle marrow involvement by mantle cell lymphoma. A, Hematoxylin and eosin staining. B, Cyclin D1 immunohistochemistry showing weak reactivity in some lymphocyte nuclei. $630 \times$.

of MALT-type lymphoma (one BM, one stomach). See Table 2.

Among benign lymphoid infiltrates of BM, spleen, and lymph node, rare individual mononuclear cells were cyclin D1 positive, but clusters of cells or distinct cell populations were not detected.

\section{DISCUSSION}

We have assessed the polyclonal H295 antibody and HIER method for evaluation of cyclin D1 expression in a variety of small B-cell infiltrates in fixed, paraffin-embedded BM, spleen, and lymph node specimens. This study was done to determine whether the sensitivity of this method may improve detection of cyclin D1 expression in MCL and HCL, particularly in marrow specimens, in which the results from studies elsewhere have been variable $(7$, $9,13,14)$.

Our results show that cyclin D1 is strongly overexpressed in MCL. Using this method, all 25 specimens (20 marrows, 2 spleens, 2 nodes, and 1 soft tissue) from 13 patients were positive (100\%). Our percentage of detection appears higher than that in other series; for example Ott et al. (15) detected 
TABLE 2. Cyclin D1 Immunohistochemistry in Bone Marrow, Spleen and Lymph Node Specimens

\begin{tabular}{|c|c|}
\hline Diagnosis \& Specimens & $\begin{array}{l}\text { Cyclin D1 Reactivity } \\
\text { Number of Patients }\end{array}$ \\
\hline \multicolumn{2}{|l|}{ Mantle Cell Lymphoma } \\
\hline Bone Marrow & $10 / 10^{*}$ \\
\hline Spleen & $2 / 2$ \\
\hline Lymph Node & $2 / 2$ \\
\hline Orbit & $1 / 1$ \\
\hline Total \# patients & $13 / 13^{* *}$ \\
\hline \multicolumn{2}{|l|}{ Hairy Cell Leukemia } \\
\hline Bone Marrow & $10 / 10$ \\
\hline Spleen & $7 / 7$ \\
\hline Total \# patients & $14 / 14^{* *}$ \\
\hline \multicolumn{2}{|c|}{ Nodal Marginal Zone Lymphoma } \\
\hline Lymph Node & $0 / 6$ \\
\hline \multicolumn{2}{|c|}{ Splenic Marginal Zone Lymphoma } \\
\hline Spleen & $0 / 5$ \\
\hline \multicolumn{2}{|l|}{ B-CLL/SLL } \\
\hline Bone Marrow & $0 / 2$ \\
\hline Spleen & $0 / 2$ \\
\hline Lymph Node & $0 / 1$ \\
\hline Total & $0 / 5$ \\
\hline \multicolumn{2}{|l|}{ MALT Lymphoma } \\
\hline Bone Marrow & $0 / 1$ \\
\hline Stomach & $0 / 1$ \\
\hline Total & $0 / 2$ \\
\hline \multicolumn{2}{|l|}{ Reactive Processes } \\
\hline Bone Marrow & $0 / 7$ \\
\hline Spleen & $0 / 1$ \\
\hline Lymph Node & $0 / 2$ \\
\hline Total & $0 / 10$ \\
\hline
\end{tabular}

* 10 were core biopsies; 6 also had clot sections.

** Some patients had bone marrow plus lymph node or spleen analyzed.

cyclin D1 immunoreactivity in $88 \%$ of cases with proven $\mathrm{t}(11 ; 14)(\mathrm{q} 13 ; \mathrm{q} 32)$, whereas Aguilera et al. (16) found immunoreactivity in $70 \%$ of 23 cases with proven translocation. According to cytogenetic and Southern blotting analyses, approximately 50 to $80 \%$ of MCL show the $t(11 ; 14)(q 13 ; q 32)$ translocation (16-18), and, according to fluorescence in situ hybridization, up to $96 \%$ show it $(19,20)$. Thus, despite the small number of cases analyzed and the likelihood that in studying a substantive number of cases, the positivity rate may fall, it appears that our conditions for the immunohistochemical detection of cyclin D1 were highly sensitive, particularly in BMs.

BM involvement based on morphology has been reported in 60 to $90 \%$ of MCL cases, with peripheral blood involvement in 25 to $50 \%$ (21). The most common pattern of infiltration has been focal intertrabecular and diffuse, but nodular and interstitial infiltrates have also been reported (21). The evaluation of marrow in patients with MCL is particularly challenging because benign lymphoid aggregates occur in 18 to $47 \%$ of BM samples. Reactive lymphoid infiltrates can also be seen in young individuals with immune disorders (22). As suggested by Swerdlow et al. (7), cyclin D1 may prove useful in detecting subtle marrow involvement and in distinguishing tumor from reactive infiltrates. Only one

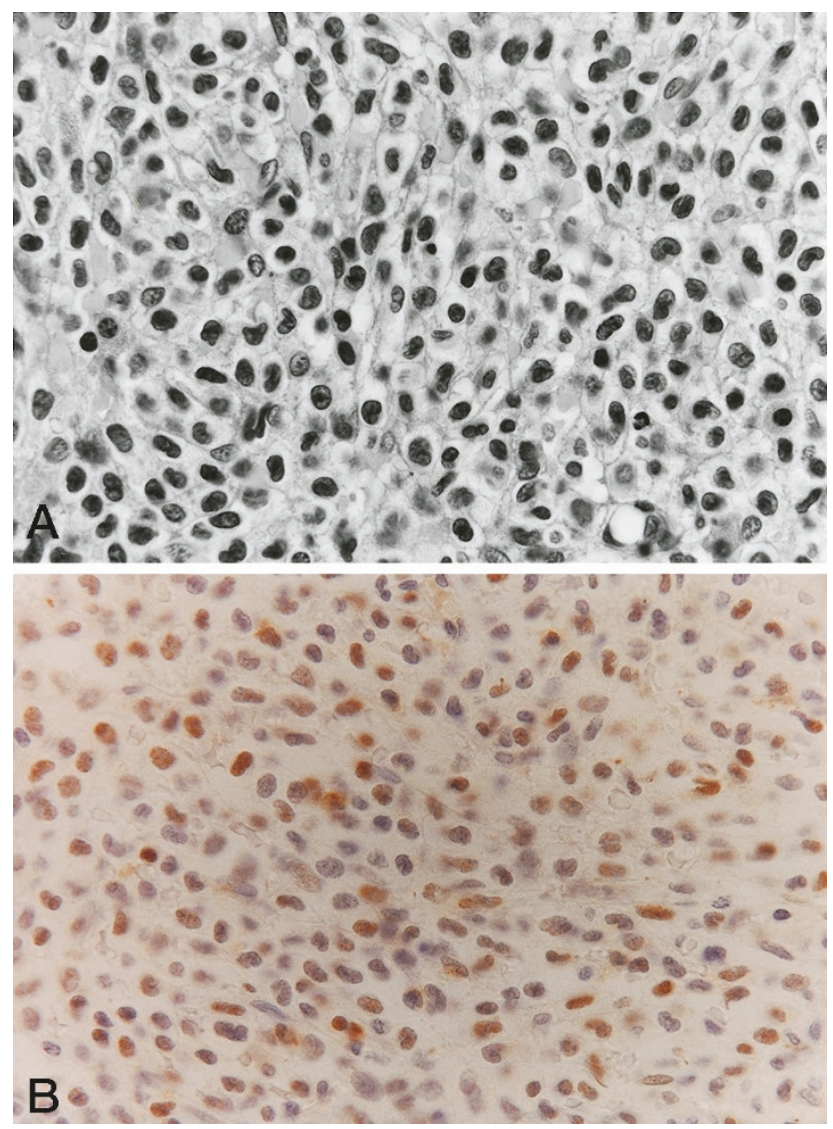

FIGURE 4. Bone marrow infiltrated by hairy cell leukemia, diffuse pattern. A, Hematoxylin and eosin staining. B, Cyclin D1 immunohistochemistry showing moderate reactivity in most lymphocyte nuclei. $630 \times$.

report has addressed the use of cyclin D1 immunohistochemistry in BM specimens, but high background staining interfered with interpretation (9). Vasef et al. (9) showed that $72 \%$ of involved marrows had cyclin D1 overexpression according to immunohistochemistry. In our cases, the pattern of $\mathrm{BM}$ involvement was predominantly nodular with a variable degree of replacement. The intensity of cyclin D1 staining was moderate in most cases, and generally more than $50 \%$ of the tumor cells were positive. Our results show that $6 / 10$ cases of MCL had less than $25 \%$ of marrow involvement, that the neoplastic cells were cyclin $\mathrm{D1}^{+}$, and that none of the lymphocytes in reactive marrows showed cyclin D1 staining, in agreement with results from other studies $(23,24)$. More recently, other approaches have been attempted to detect BM involvement; Remstein et al. (19) and Caraway et al. (25), in abstract forms, showed that fluorescence in situ hybridization is highly sensitive for detection of BM involvement by MCL, up to 96\%; Caraway et al. (25) showed that fluorescence in situ hybridization can detect $\mathrm{t}(11 ; 14)$ breakpoints when polymerase chain reaction is negative.

Cyclin D1 overexpression is not limited to MCL but is also seen in a subset of carcinomas of the 
head and neck, breast, and lung $(6,7)$. Although most lymphoproliferative disorders other than MCL do not express cyclin D1, there have been reports of cyclin D1 overexpression in HCL, although the results have been inconsistent. Vasef et al. (9) found that $1 / 5(20 \%)$ cases of HCL reacted. Zukerberg et al. (14) found cyclin D1 overexpression in 1/15 HCL cases. Savilo et al. (13), in a recent abstract, mentioned that cyclin D1 was commonly overexpressed in HCL. The reasons for this variability in detecting cyclin D1 are likely due to differences in methodologies, including conditions of antigen retrieval and antibody specificity. Vasef et al. (9) used a cocktail of two monoclonal antibodies (P2D11F11 and 5D4), protease digestion, and heat and sonication-induced epitope retrieval; Zukerberg et al. (14) used a polyclonal antibody that was produced in their laboratory, combined with microwave epitope retrieval; Savilo et al. (13) used a monoclonal antibody clone ZY-7D2.

The finding of high cyclin D1 protein expression in HCL is not entirely unexpected. Bosch et al. (26) reported high levels of cyclin D1 mRNA and protein overexpression using Western blot analysis, although they noted that the level of expression in HCL was much lower than in MCL and that it was a bcl-1 rearrangement. More recently, Aguilera et al. (16) assayed cyclin D1 mRNA by reverse transcriptase polymerase chain reaction to show very high levels of transcripts in MCL but lower levels in other lymphoproliferative disorders, including 6/11 follicular center cell lymphoma, 2/3 peripheral $\mathrm{T}$ cell lymphoma, and $2 / 3$ diffuse large cell lymphoma. These authors, however, did not find cyclin D1 protein overexpression in follicular center cell lymphoma or peripheral T-cell lymphoma, including anaplastic large-cell lymphoma; HCL was not tested.

It has been reported elsewhere that other small B-cell neoplasms, including B-CLL/SLL, SMZL, or MALT lymphoma, do not, or only rarely, express cyclin D1 by immunohistochemistry (7). Cyclin D1 is expressed in $6 \%$ or less of B-CLL/SLL, in agreement with our results. It has also been reported that about 20 to $30 \%$ of lymphoplasmacytic lymphoma and multiple myeloma may overexpress cyclin D1 $(27,28)$. Similar to the case with other investigators, we did not find cyclin D1 reactivity in SMZL (29) and marginal zone lymphoma of nodes and stomach $(15,23)$.

In conclusion, HIER using the H295 antibody is a very sensitive method for detecting cyclin D1 expression in fixed tissue in all tissue types, including BM. Cyclin D1 expression is moderate to strong in MCL and is present at a weaker level in all HCL tested. Reactive tissue and other small B-cell neoplasms are negative. Although the number of cases studied is small, we show evidence that this tech- nique is useful, particularly in the marrow in detecting minimal disease and in differentiating MCL and HCL from reactive lymphoid infiltrates and other small B-cell neoplasms. Cyclin D1 expression in HCL may be useful in diagnosing this disease when flow cytometry is not available. Also, immunostaining for cyclin D1 can identify follicular colonization by MCL, which may cause confusion with a low-grade follicular lymphoma.

\section{REFERENCES}

1. Harris NL, Jaffe ES, Stein H, Banks PM, Chan JKC, Cleary ML, et al. A revised European-American classification of lymphoid neoplasms: a proposal from the International Lymphoma Study Group. Blood 1994;84:1361-92.

2. Lukes RJ, Collins RD. Tumors of the hematopoietic system. In: Atlas of tumor pathology. Second Series, Fascicle 28. Washington, DC: Armed Forces Institute of Pathology, 1992.

3. Warnke RA, Weiss LM, Chan JKC, Cleary ML, Dorfman RF. Tumors of the lymph nodes and spleen. In: Atlas of tumor pathology. Third Series, Fascicle 14. Washington, DC: Armed Forces Institute of Pathology, 1995.

4. Teodorovic I, Pittaluga S, Kluin-Nelemans JC, Meerwaldt JH, Hagenbeek A, van Glabbeke M, et al. Efficacy of four different regimens in 64 mantle-cell lymphoma cases: clinicopathologic comparison with 498 other non-Hodgkin's lymphoma subtypes. European Organization for the Research and Treatment of Cancer Lymphoma Cooperative Group. J Clin Oncol 1995;13:2819-26.

5. Zucca E, Rogerro E, Pinotti G, Pedrinis E, Cappella C, Venco A, et al. Patterns of survival in mantle cell lymphoma. Ann Oncol 1995;6:257-62.

6. Swerdlow SH, Williams ME. Centrocytic lymphoma: a distinct clinicopathologic, immunophenotypic, and genotypic entity. Pathol Annu 1993;28:171-97.

7. Swerdlow SH, Yang W-I, Zukerberg LR, Harris NL, Arnold A, Williams ME. Expression of cyclin D1 protein in centrocytic/ mantle cell lymphomas with and without rearrangement of the bcl-1/cyclin D1 gene. Hum Pathol 1995;26:999-1004.

8. Rosenberg CL, Wong E, Petty EM, Bale AE, Tsujimoto Y, Harris NL, Arnold A. PRAD1, a candidate BCL1 oncogene: mapping and expression in centrocytic lymphoma. Proc Natl Acad Sci U S A 1991;88:9638-42.

9. Vasef MA, Medeiros LJ, Koo C, McCourty A, Brynes RK. Cyclin D1 immunohistochemical staining is useful in distinguishing mantle cell lymphoma from other low-grade B-cell neoplasms in bone marrow. Am J Clin Pathol 1997;108:302-7.

10. Cousar JB, McGinn DL, Glick AG, List AF, Collins RD. Report of an unusual lymphoma arising from parafollicular B-lymphocytes (PBLs) or so called "monocytoid" lymphocytes. Am J Clin Pathol 1987;87:121-8.

11. Hammer RD, Glick AD, Greer JP, Collins RD, Cousar JB. Splenic marginal zone lymphoma. A distinct B-cell neoplasm. Am J Surg Pathol 1996;20:613-26.

12. Shi SR, Key ME, Kalra KL. Antigen retrieval in formalin-fixed, paraffin embedded tissues: an enhancement method for immunohistochemistry based upon microwave oven heating of tissue sections. J Histochem Cytochem 1991;39:741-8.

13. Savilo E, Nguyen PL, Harris NL. Cyclin D1 expression in hairy cell leukemia [abstract]. Mod Pathol 1998;11:140A.

14. Zukerberg LR, Yang W-I, Arnold A, Harris NL. Cyclin D1 expression in non-Hodgkin's lymphomas. Detection by immunohistochemistry. Am J Clin Pathol 1995;103:756-60. 
15. Ott MM, Helbing A, Ott G, Bartek J, Fischer L, Durr A, et al. bcl-1 rearrangement and cyclin D1 protein expression in mantle cell lymphoma. J Pathol 1996;179:238-42.

16. Aguilera NSI, Bijwaard KE, Duncan B, Krafft AE, Chu W-S, Abbondanzo SL, et al. Differential expression of cyclin D1 in mantle cell lymphoma and other non-Hodgkin's lymphomas. Am J Pathol 1998;153:1969-76.

17. Weisenburger DD, Armitage JO. Mantle cell lymphoma-an entity comes of age. Blood 1996;87:4483-94.

18. Yatabe Y, Suzuki R, Tobinai K, Matsuno Y, Ichinohasama R, Okamoto M, et al. Significance of cyclin D1 overexpression for the diagnosis of mantle cell lymphoma: a clinicopathologic comparison of cyclin D1-positive MCL and cyclin D1negative MCL-like B-cell lymphoma. Blood 2000;95:2253-61.

19. Remstein ED, Buno I, Bailey R, Kurtin PJ, Proffitt J, Dewald GW. Diagnostic utility of fluorescence in situ hybridization (FISH) versus polymerase chain reaction (PCR) in mantle cell lymphoma [abstract 943]. Mod Pathol 2000;13:161A.

20. Vaandrager J-W, Schuuring E, Zwikstra E, de Boer CJ, Kleiverda KK, van Krieken JH, et al. Direct visualization of dispersed 11q13 chromosomal translocations in mantle cell lymphoma by multicolor DNA fiber fluorescence in situ hybridization. Blood 1996;88:1177-82.

21. Wasman J, Rosenthal NS, Farhi DC. Mantle cell lymphoma. Morphologic findings in bone marrow involvement. Am J Clin Pathol 1996;106:196-200.

22. Brunning RD, McKenna RW. Tumors of the bone marrow. In: Atlas of tumor pathology, Third Series, Fascicle 9. Washington, DC: Armed Forces Institute of Pathology, 1993;40916.
23. Yang W-I, Zukerberg LR, Motokura T, Arnold A, Harris NL. Cyclin D1 (Bcl-1, PRAD1) protein expression in low-grade B-cell lymphomas and reactive hyperplasia. Am J Pathol 1994;145:86-96.

24. Brynes RK, McCourty A, Tamayo R, Jenkins K, Battifora H. Demonstration of cyclin D1 (Bcl-1) in mantle cell lymphoma. Enhanced staining using heat and ultrasound epitope retrieval. Appl Immunohistochem 1997;5:45-8.

25. Caraway NP, Medeiros LJ, Gu J, Luthra R, Romaguera J, Katz RL. Utility of fluorescence in-situ hybridization (FISH) to detect cyclin D1 breakpoints in staging peripheral blood (PB) and bone marrow (BM) specimens of patients with mantle cell lymphoma (MCL) negative by PCR for MTC bcl-1/JH DNA fusion sequences [abstract \#840]. Mod Pathol 2000;13:144A.

26. Bosch F, Campo E, Jares P, Pittaluga S, Muñoz J, Nayach I, et al. Increased expression of the PRAD-1/CCND1 gene in hairy cell leukemia. Br J Haematol 1995;91:1025-30.

27. Lai R, Medeiros LJ, Wilson CS, Sun NC, Koo C, McCourty A, et al. Expression of the cell-cycle-related proteins E2F-1, p53, mdm-2, p21waf-1, and Ki-67 in multiple myeloma: correlation with cyclin-D1 immunoreactivity. Mod Pathol 1998;11: $642-7$.

28. Jadayel D, Matutes E, Dyer MJ, Brito-Babapulle V, Khohkar MT, Oscier D, et al. Splenic lymphoma with villous lymphocytes: analysis of BCL-1 rearrangements and expression of the cyclin D1 gene. Blood 1994;83:3664-71.

29. Savilo E, Campo E, Mollejo M, Pinyol M, Piris MA, Zukerberg LR, et al. Absence of cyclin D1 protein expression in splenic marginal zone lymphoma. Mod Pathol 1998;11:601-6.

\section{Book Review}

\section{Owen OA, Kelly JK: Pathology of the Gallblad- der, Biliary Tract and Pancreas, Volume 39 of the Major Problems in Pathology Series, 365 pp, Philadelphia, W.B. Saunders, 2001 (\$79.00).}

As astutely pointed out by the authors in the preface, the pathology of the gallbladder, biliary tract, and pancreas is an area that has few dedicated monographs. This text provides a comprehensive overview of the region. As many surgical pathologists will attest, a scheduled Whipple procedure sends one scrambling for texts dedicated to this subject. The widespread use of this procedure as well as endoscopic techniques ensure that the pathologist must be adequately prepared to interpret tissue specimens from this region. Not to mislead though, this book covers all aspects of disease, not just neoplasia.

Contents include 16 chapters within 351 pages followed by a comprehensive index. Chapters are thoughtfully arranged with reviews of embryology, anatomy, and histology of the pancreas, gallbladder, and bile ducts followed by chapters dealing with neoplastic, congenital, in- flammatory, and degenerative conditions. The complex features and lesions of the ampulla of Vater are included. The inclusion of discussion and illustrations of normal anatomic variants is well done. Also nicely incorporated into the text is information regarding contemporary molecular and clinical caveats with an entire chapter dedicated to the molecular biology of pancreatic carcinoma. This text does well to not only describe and classify but to expand on etiology and pathogenesis. The illustrations of the text are primarily directed toward histopathology, although gross and cytology pictures are included. The illustrations are limited to black and white and are labeled clearly.

Overall, I find this book to be a quintessential guide for pathology residents, fellows, and practicing pathologists dealing with pancreatobiliary specimens. This volume continues in the highquality tradition of the MPP series.

\author{
Jay C. Helsel \\ University of Kansas Medical Center \\ Kansas City, Kansas
}

